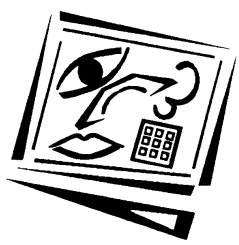

\title{
Increasing online interaction in a distance education MBA: Exploring students' attitudes towards change
}

\author{
Sharon Watson \\ Chifley Business School
}

\begin{abstract}
This paper reports the results of the first phase of a mixed methods study investigating the attitudes of students enrolled in a distance education MBA program towards interacting more with other students online. It grapples with the issue of whether students enrolled in a successful distance education program grounded in instructivist and constructivist pedagogy would support changes to its design centring around social-constructivist theory. In this phase, a predominantly quantitative online survey was administered to 316 students. The most significant finding was a division in attitudes according to nationality and location, with Indian respondents less satisfied with the status quo and more interested in changes than their Australian counterparts. This raises the possibility of a fundamental difference in the attitudes, expectations and preferences of Australian and Indian distance education students. However, the results also show that if changes of the nature suggested were made, most respondents would not consider withdrawing from the MBA program.
\end{abstract}

\section{Introduction}

This paper reports the results of the first phase of a mixed methods study investigating the attitudes of students enrolled in a distance education Master of Business Administration (MBA) program towards engaging in greater online interaction with other students. The program is delivered by Chifley Business School, the training arm of the Association of Professional Engineers, Scientists and Managers, Australia (APESMA). It currently has almost 1000 enrolled students located around Australia and across the globe.

From its print based beginnings, the program has evolved to include supplementary online asynchronous discussion forums known as e-Communities. Each e-Community is divided into a series of topics related to the content and assessment for a given unit. Many also include a 'coffee club' discussion area where students can interact socially about matters beyond their studies. The e-Community for each unit is facilitated by an academic who initially posts an introduction and encourages students to do the same. The print based materials for each unit and the welcome email from the course administrator also encourage students to access e-Communities and provide them with clear directions for doing so. The facilitation approaches of the academics vary, with some posting questions for each topic, others posting topical articles as discussion starters and a few posting scenarios designed to engage students in discussions about how the unit's concepts work in the real world of business practice. However, regardless of the facilitation approach used by the academic, for most units in the program, minimal discussion occurs on e-Communities, and the little that does occur 
tends to be between the students and the academics rather than between the students themselves.

This outcome is consistent with the educational design of the MBA units, which is based on an instructional model that emphasises instructivist and constructivist pedagogy, but not social-constructivist pedagogy. Students are provided with substantial print based learning materials that step students through each unit. Content is generally internationalised, and learning and assessment activities frequently require students to apply key concepts to their own work contexts, real organisations or real events. However, independent learning activities are generally privileged over those involving social interaction, and students' online participation is not assessed.

After observing the vibrancy of the online discussion forums in a Master of Education delivered by another provider, the MBA program's educational designers began considering whether to change this design to encourage greater online interaction between students. However, reshaping the underpinning pedagogy of distance education units is complex, and little was known about whether the students' in fact desired such a change or instead chose the program precisely because they were free to study independently without interacting extensively with others, or dealing with the associated temporal constraints. Given that Chifley Business School is a private provider, there is considerable financial risk involved in making design changes without reasonable data indicating that such changes would be well received by students. The broader literature in this area is inconclusive and is dominated by studies that explore the views of students enrolled in courses that have already changed their pedagogical design rather than those considering doing so. This study was therefore undertaken to develop an understanding of the students' attitudes and determine whether they would be likely to respond positively if the design of units in the program was changed to promote increased levels of online interaction between students.

\section{Literature review}

\section{Changing models of interaction in distance education courses}

Moore (1993) identified three types of interactions that occur in distance education: those between students and subject content, those between students and academics, and those between the students themselves. Until relatively recently, opportunities for interaction between students in distance education programs were limited. The design of such programs therefore tended to follow the instructional model (Okada, 2005) and focus heavily on facilitating student interaction with the subject content.

During the past 15 years, the rapid spread of the Internet has made it possible for distance education students to interact daily with each other if desired. During a similar period, social-constructivist pedagogy has gained prominence through the works of Vygotsky (1978), Duffy and Jonassen (1992) and Holmes, Tangney, FitzGibbon, Savage and Mehan (2001), amongst others. Whilst all constructivist theorists argue that learners actively construct knowledge by linking new information to their existing knowledge base, social-constructivist theorists place a particular emphasis on the role of social interaction in this process. The combination of these trends has facilitated the creation of two new models of design for distance education 
programs: the interactive model and the collaborative model (Okada, 2005). Both place an increased emphasis on facilitating interaction between students online.

\section{Online and distance education students' attitudes towards interacting with other students}

In the body of research investigating students' attitudes towards interacting with other students in online and distance education courses, there are some studies that report overwhelmingly positive attitudes. For example, O'Reilly and Newton (2002) found the majority of their 90 survey respondents highly valued interaction with peers and reported a wide range of benefits including mutual support, friendships, a reduced sense of isolation and new insights into the concepts being studied. Yildiz and Chang (2003) similarly reported that most of the 20 respondents to their survey perceived they learnt a lot from their peers and received more immediate and higher quality peer feedback than in face to face courses.

However, as research in this area matures, findings are becoming more complex. Studies by Motteram and Forrester (2005), Fung (2004) and Kear (2004) all show that whilst some students gain support and reassurance from interacting with other students, others place little value on such activities or struggle to find the time to engage in them due to work and family commitments. In a study that captures this duality and ambivalence particularly well, Su, Bonk, Magjuka and Lee (2005) found that whilst $94 \%$ of the 102 MBA students they surveyed thought interacting with other students enhanced their learning experience, the extent to which they actually desired and engaged in such interactions varied greatly and they generally accepted lower interaction levels as a natural result of their multiple commitments. This tendency for students to not actually post messages is also reported by Kear (2004) who found many students thought they had nothing to say that had not already been said by others. Such impulse control can be positive; qualitative comments gathered by Hatch (2002) record students' frustration at spending time reading what they perceive to be irrelevant or superfluous discussion posts. Hatch (2002, p. 247) further reports one student saying they had "moved to distance learning to get away from the interaction". Each of these studies appears to support the contention of Anderson (2002) that students' need for interactivity varies. They also lend weight to his theory that meaningful learning will occur so long as any one of the three types of interactions identified by Moore (1993) are present at high levels, and that whilst achieving high levels of two or more types of interactions may provide a better or more satisfying educational experience, it may also be more time-consuming which can be problematic for some students.

Only one inquiry to date has explored the effects of this new style of course design on students with a 'solitary' cognitive style. In their phenomenological study into the experiences of five solitary learners, Ke and Carr-Chellman (2006) found that whilst these students valued the multiple perspectives provided by online discussions with peers, they still preferred independent learning activities such as reading and disliked being forced into interdependence. Their findings are congruent with those of BeythMarom, Saporta and Caspi (2005) who explored the relationship between 165 distance education students' learning styles, preference for synchronous or asynchronous, satellite based tutorials, and attitudes towards interaction. They found that whilst the student group as a whole did not place a high value on interactions with other students or their tutors, those who preferred synchronous tutorials were much more likely to place a higher value on interaction and much less likely to value their 
autonomy or sense of control within the learning process. This is effectively the reverse image of Ke and Carr-Chellman's solitary students who placed a low value on interaction with other students and a high value on autonomy within the learning process. Beyth-Marom et al. concluded that there was a strong correlation between students' learning style preferences, delivery preferences and attitudes towards interaction, and that no single pedagogy or learning environment could meet the needs of all students.

A similarly complex picture emerges from Liu's (2008) phenomenological study of the interaction experiences of five students enrolled in distance education courses. Liu found that the level of interaction between students was affected by five interrelated factors: students' learning styles and preferences; the instructor's teaching style and course design; students' perception of the nature of distance education courses; the course subject matter and level of difficulty; and the way students managed their time and other commitments. As with many of the other studies cited, Liu reported that whilst some students enjoyed interacting with other students, others preferred to study independently and keep interaction to a minimum. In some cases this reflected a choice to study by distance in order to balance multiple commitments, and a consequent reluctance to invest time in interacting with other students, unless there was a clear reason for doing so. Low levels of interaction between students therefore tended to have little impact on independent learners, whilst for social learners it led to a decreased interest in the course.

A rather different perspective is offered by Kelsey and D'Souza (2004) who investigated the experiences of 31 students completing postgraduate agriculture courses by distance education. In their study, formal interactions between students were not built into the majority of the courses, but could occur through email, video conferencing and an online learning system. Disappointingly, despite purporting to explore whether interactions between learners facilitated favourable learning outcomes, Kelsey and D'Souza did not publish either the questions they asked participants or any details of the results. Instead, they simply reported that the students had not considered interactions with other students important to them or critical to their success in the course. They concluded that whilst staff needed to do more to encourage such interactions, the question nevertheless needed to be asked whether distance education students were really interested in interacting with other students enrolled in the same course. Whilst the validity of Kelsey and D'Souza's conclusions are difficult to ascertain, they nevertheless bring us full circle to questions that are at the heart of this study: to what extent do students enrolled in traditional distance education courses that have yet to adopt the new interactive model of design desire greater interaction with other students; would design changes to facilitate such an outcome be welcomed, or would they be seen as imposing the latest pedagogical trends on an unwilling and disinterested cohort who prefer the status quo?

Within the literature, the phenomenological studies by Ke and Carr-Chellman (2006) and Liu (2008) provide by far the richest depictions of distance education students' attitudes towards interacting with other students; however, by virtue of being a qualitative methodology that focuses on a small number of subjects, phenomenological studies are unable to reveal the proportion of students who hold different views and preferences. By using a mixed methodology to initially survey a large cohort of distance education students and then interview a small sample of these in more depth, this study seeks to achieve some of the richness of the phenomenological studies 
whilst also revealing the proportion of students who hold different views and preferences.

\section{Online and distance education students' preferred modes of communication for interacting with other students}

Online and distance education students vary not only in the extent to which they desire interaction with other students, but also in their preferred modes of communication for doing so. In a wide-ranging exploration of more than 400 technology-savvy students' perspectives on e-learning, JISC (2007) reported mixed responses to discussion board and chat technologies. They found that some students' reticence in using asynchronous discussion boards stemmed not from a disinterest in interacting with other students, but rather from a preference for using publicly available synchronous communication technologies such as Skype, MSN Messenger, My Space and their mobile phones resulting in a parallel 'underworld' of private communication not visible to the institutions.

A preference for synchronous, non-text based communication also emerged as a theme in studies of online students conducted by Stodel, Thompson and MacDonald (2006) and Kim, Liu and Bonk (2005). Stodel et al. found that some students missed the nonverbal cues, physical presence and informal social interactions afforded by face to face communication and thought the asynchronous discussion boards were slow and lacking in spontaneity whilst the synchronous chatroom was too reliant on speed typing. Kim et al. (2005) similarly reported that some of the students they interviewed found telephone conversations with other students easier and less convoluted than email. Such preferences may well be influenced by students' Jungian personality type; a study by Lin, Cranton and Bridglall (2005) shows that students who are strong extraverts, and students who use their senses more than their intuition to understand the world, tend to miss physical presence and non-verbal interactions far more than students of other personality types. It is important to note, however, that not all students share such views, and Stodel et al. (2006) point to Anderson's (2004) observation of "a deep division between those who yearn for the immediacy of realtime communication, and those who are adamant that they have chosen online learning alternatives to avoid the time constraints imposed by synchronous ... activities"' (p. 279).

These studies suggest there is a complex interrelationship between students' attitudes towards interacting with other students, their personalities, their learning styles and the communication technologies provided by institutions. A critical implication for this study is that low levels of student interaction on asynchronous discussion forums may not necessarily indicate student disinterest in interacting with other students, but may instead reflect their preference for interacting synchronously through other means. This study therefore explores students' attitudes towards interacting with each other in a range of modes and contexts rather than only through the asynchronous online discussion forums currently provided.

\section{Methodology}

A sequential, two phase, mixed methodology using an explanatory design (Creswell \& Plano Clark, 2007) was chosen for this study. A diagrammatic representation of the methodology is shown in Figure 1. 


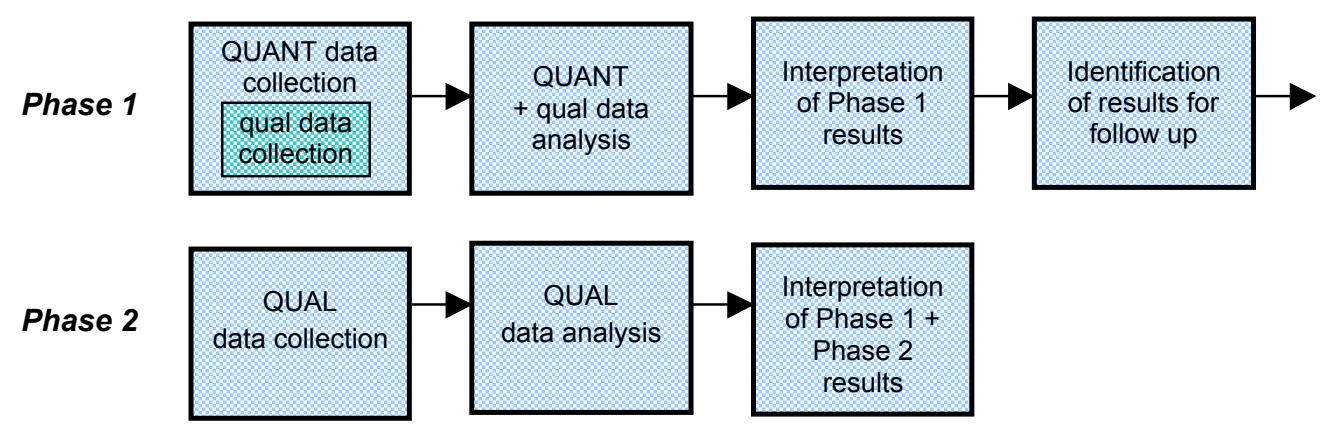

Figure 1: Methodology

This paper reports the results of the first phase of this project in which a concurrent nested strategy (Creswell, 2003) was used to develop a predominantly quantitative online survey that included four questions with qualitative components. The survey is shown in the appendix and was designed to address the six project questions:

1. How often do students enrolled in the MBA program actively participate in eCommunities discussions involving other students?

2. How does their level of active participation in e-Communities discussions compare with how often they read e-Communities discussion postings?

3. How satisfied are students with the current nature and level of interaction between students that is occurring on the e-Communities discussion forums for the MBA program?

4. To what extent do students interact regularly with other students enrolled in the MBA program outside the e-Communities discussion forums, and what modes of communication do they use?

5. What are the key reasons students do or don't interact with other students, whether on e-Communities or through other modes of communication?

6. Would students be likely to respond positively if the design of the MBA units was changed to facilitate and encourage more frequent meaningful online interaction between students, whether using e-Communities or other online communication tools?

The structure of the survey reflects Rosenberg's (1968) notion that social research is an exploration of the relationships between a population's social properties (Survey Part A), dispositions (Survey Part B) and intended actions (Survey Part C). The survey was trialed by staff members from Chifley Business School who had previously completed units in the MBA program and were able to provide informed comments. Their feedback was used to refine the survey and improve its reliability and validity.

A total of 316 students enrolled in six different MBA units were contacted by email by the program's administrator, Chifley Business School, and invited to participate in the survey. The units were selected using a stratified cluster sampling procedure aimed at maximising the likelihood the sample would capture the views of students at different stages and with differing levels of experience in the program. The invitational email to students included a web link to the survey which was administered using a commercial online survey host, SurveyMonkey. Ethics approval for the study was provided by the University of Southern Queensland. 


\section{Data analysis procedures}

A univariate descriptive analysis of the quantitative survey data was undertaken to summarise the results for each question. Data was recoded by combining categories as required to facilitate a subsequent bivariate analysis aimed at identifying patterns within the data. Distributions of the respondents' demographic variables were crosstabulated with their attitudinal variables and future orientation variables. The coefficients phi, Cramer's $V$ and Goodman and Kruskal's gamma were used to measure associations between variables as appropriate.

Responses to the four survey questions that included qualitative components were coded to identify emergent themes. Frequency counts were used to summarise the results and were complemented by a selection of direct quotes from respondents to illustrate each of the key themes. Each respondent was given an alphanumeric identity to preserve confidentiality.

\section{Results}

\section{Demographics and sample representativeness}

Of the 316 students surveyed, 75 responded giving a response rate of $24 \%$. Only one respondent did not complete all survey questions. Respondents included students at all stages in the MBA program and their gender distribution, age distribution and employment profile very closely resemble those of the broader student body. The only apparent difference between the demographics of the respondents and those of the broader student population was that students living in Australia were slightly underrepresented whilst Indian students living in the Middle East were over-represented. However, this outcome is consistent with results presented in this paper, which suggest that Australian students tend to be less participatory and less interested in change than their Indian counterparts, particularly those located in the Middle East.

All respondents use the Internet at least once a week and almost two thirds do so each day. Most use a high speed connection, although three still have only access to dialup. More than $85 \%$ of respondents travel and spend time away from home during their studies, with almost a third doing so often. Almost half of those who travel do not have reliable access to the Internet whilst they are away.

\section{Frequency of interacting with other students using e-Communities}

Almost $70 \%$ of respondents reported reading e-Communities discussion items at least once a week when studying, but less than $10 \%$ said they posted discussion items to other students that often. The bivariate analysis showed a moderate association between location and frequency of posting $(V=0.316$, sig $=0.18)$, with respondents in Australian capital cities and the Middle East tending to post less regularly than those located elsewhere.

Two clear themes emerged from respondents' brief explanations as to why they posted this little:

1. Reasons related to personal circumstances and preferences

2. Reasons that can be attributed to course design or delivery. 


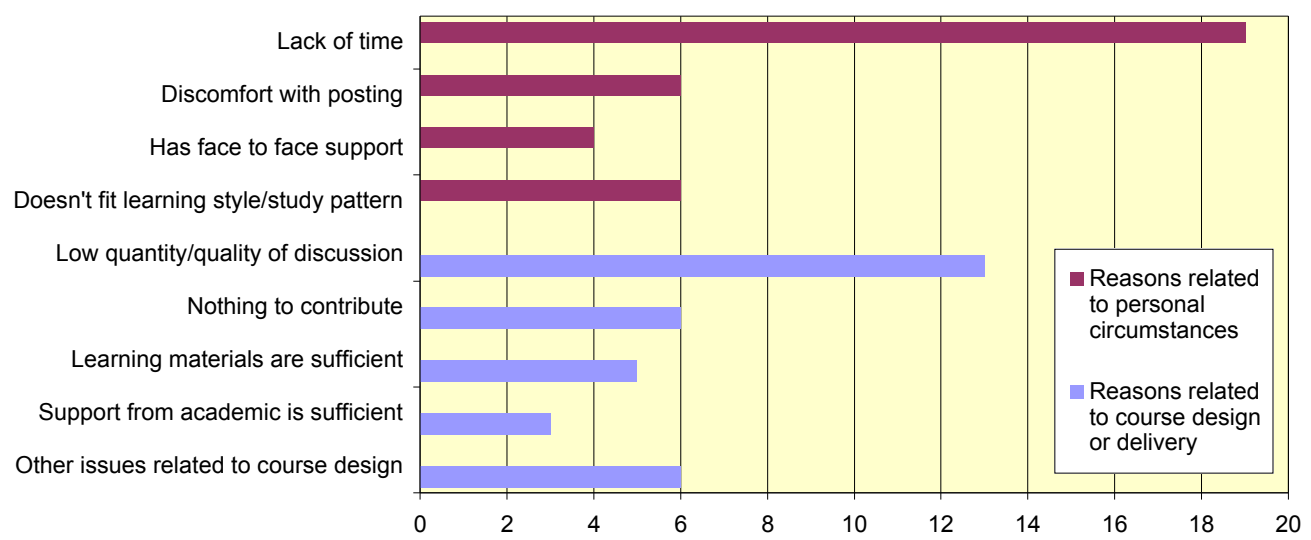

Figure 2: Reasons for not posting

Of the reasons related to personal circumstances, the most often reported was lack of time as shown in Figure 2. Representative comments included:

I have very limited time to study with juggling other family commitments, so if I don't think the interaction will benefit my study, then I don't post anything... (S33)

Of the reasons that can be attributed to the effects of the underlying course design, the most often reported was the low quantity or quality of discussion posts from other students. Representative comments included: "Little or no interaction online - few students providing inputs" (S2) and "Don't feel the need to get involved in the discussion as some of it is fairly pedestrian" (S8).

In some cases, course design and personal circumstances come together to prevent students from posting:

I only have limited amount of time to study, and for most subjects doing reading, text exercises and assignments takes up all available time. (S24)

\section{Satisfaction with quantity and quality of e-Communities discussions between students}

Respondents were divided regarding the extent to which they were satisfied with the quantity and quality of discussion between students on e-Communities. Figures 3 and 4 show that about half were satisfied, slightly more than a third were dissatisfied and the remainder were indifferent. The bivariate analysis showed no significant association between respondents' demographics and their level of satisfaction.

Themes from respondents' comments on the quantity and quality of discussion varied according to their level of satisfaction. Of those respondents who were satisfied with the amount of discussion between students, many expressed a general belief that other students' comments and questions were useful. Others offered justificatory explanations for the level of discussion, typified by the following comment:

Discussions are very less probably because everyone is busy and they do not find much time to write on e-communities. It's the same with me. (S34) 


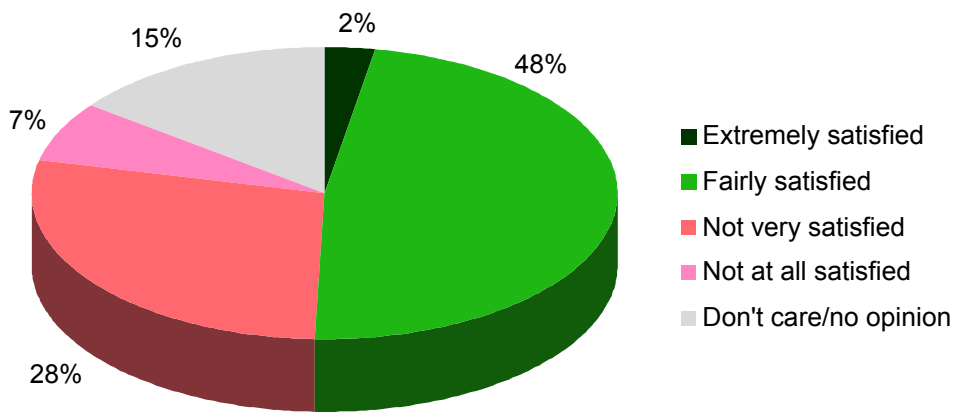

Figure 3: Satisfaction with quantity of discussion

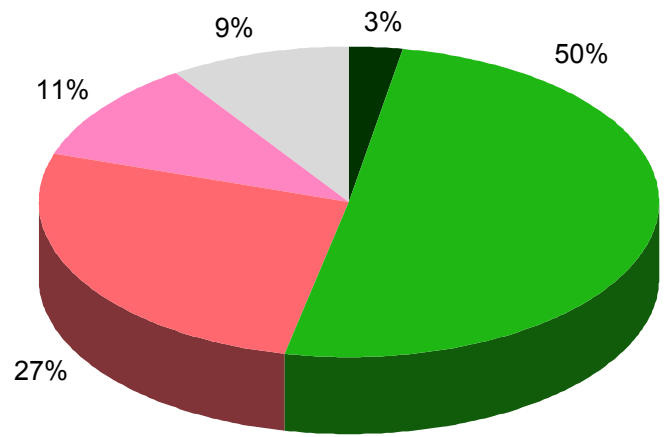

Extremely satisfied

Fairly satisfied

Not very satisfied

Not at all satisfied

Don't care/no opinion

Figure 4: Satisfaction with quality of discussion

Of the respondents who were either dissatisfied with or indifferent about the amount of discussion, most expressed a general dissatisfaction with the lack of participation and interaction. One respondent noted the inhibitory climate this created, saying: "If there was more discussion I might feel less awkward about joining in" (S7). Another respondent indicated a preference for face to face social activities whilst others expressed a desire for a richer learning experience involving less interaction with the academics and more interaction with peers:

The lack of student interaction and peer learning is a big portion of education and this is very limited over the internet. (S6)

Of those who were satisfied with the quality of discussions, most indicated they enjoyed having access to others' experiences and views, and that other students' posts helped them learn and complete their assignments. Several commented that e-Communities was a positive and safe environment in which all contributions were welcome.

Of those respondents who were either dissatisfied with or indifferent about the quality of discussions, most commented either that few postings mean few quality discussions or that the discussions that do occur are mundane and lacking in depth. One 
respondent remarked: “Conversations are generally very limited and do not probe real issues" (S6).

\section{Interacting with other students beyond e-Communities}

Almost $30 \%$ of respondents said they interacted with other students outside eCommunities, as shown in Figure 5. Most do so in person, by telephone or by email and half use two or more modes of communication. However, only two use the online synchronous technologies Skype or instant chat and in both cases this was in addition to two or three other modes of communication. The bivariate analysis showed no association of significance between respondents' demographics and their tendency to interact outside e-Communities.

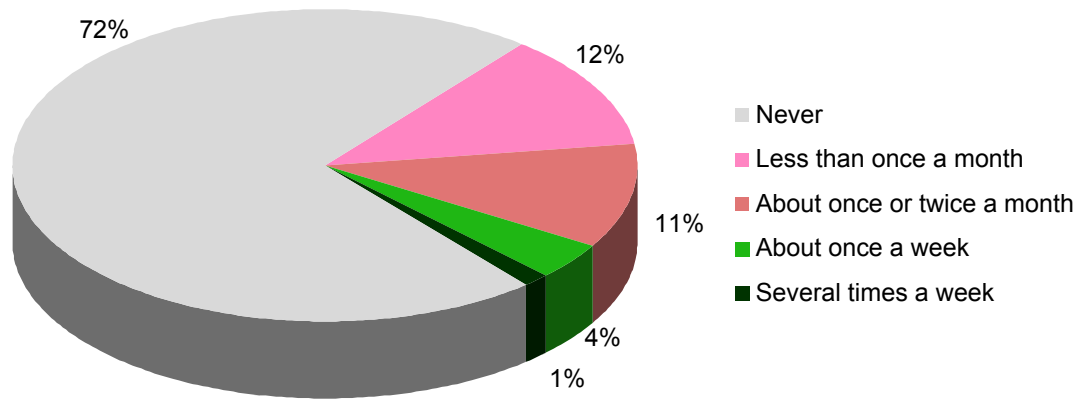

Figure 5: Frequency of interacting outside e-Communities

The most common reason cited for interacting with students outside e-Communities was that discussing the course with others enriched the learning experience. Representative comments included:

It is a good opportunity to discuss the learning objectives of the week's topic, discuss the relevance of this issues and how they relate to current affairs. (S36)

I like face to face communication. I feel you can explain answers/ questions better. You can mind map and scribble on white boards etc. (S9)

Other reasons cited included gaining moral support from others who are similarly trying to juggle study, work and family, and using positive pressure from peers to keep up with the study schedule. For some respondents, such interactions were simply a natural extension of existing friendships or professional networks; for others, they represented an opportunity to develop new friendships and networks in a way not possible through e-Communities:

The way e-Communities is segregated by unit does not allow for an ongoing relationship between students during the course of study - like being able to ask student what they thought of elective units etc. (S63)

\section{Attitudes towards alternative ways of interacting}

Respondents were presented with four options regarding different ways they might like to interact with each other in the future. Figure 6 shows that only one option 
garnered a clearly positive response, with almost $60 \%$ of respondents indicating they would like to share files and pictures with other students more easily and most other respondents expressing indifference but not disagreement. Although the other options drew more mixed responses, the bivariate analysis showed a moderate association between respondents' nationality or location and the extent to which they agreed they would like to be able to see and hear other students $(V=0.333$ for nationality, sig = $0.034 ; V=0.334$ for location, sig $=0.006$ ). Indian respondents, particularly those living in the Middle East, tended to indicate agreement, whilst Australian respondents tended to indicate disagreement or indifference.

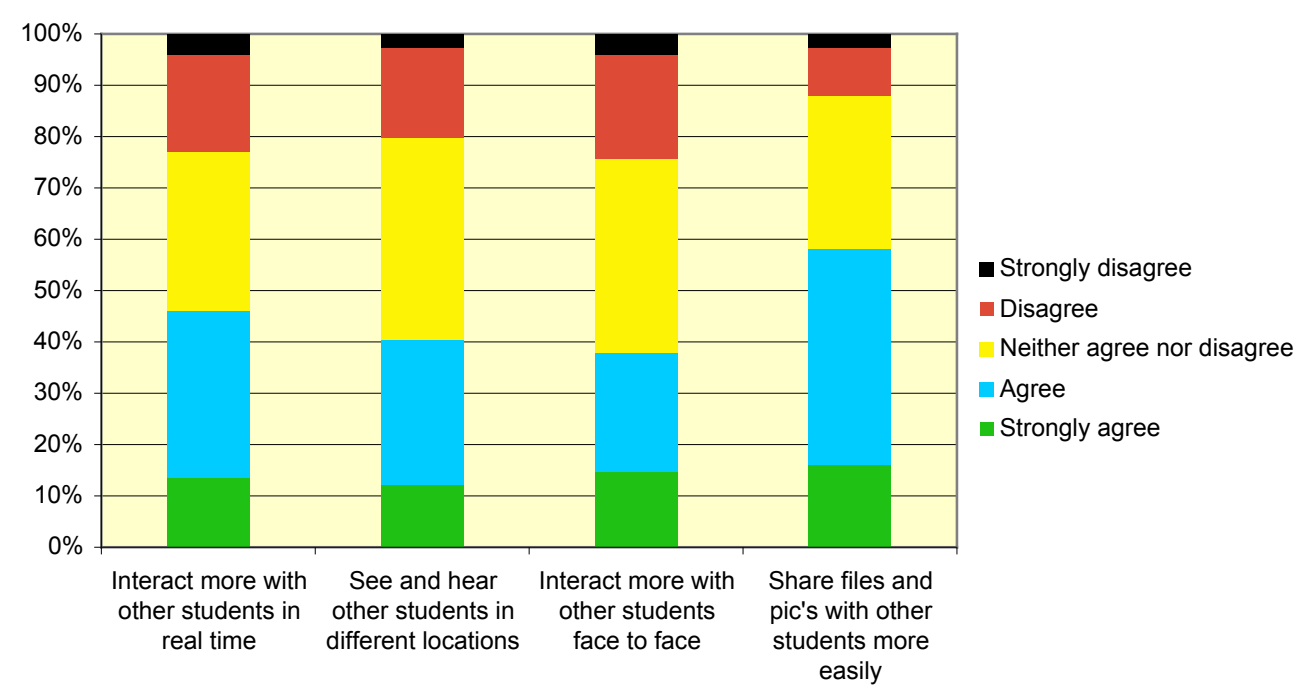

Figure 6: Responses to the statements "I would like to be able to..."

Given that facilitating different ways for students to interact would likely require Chifley to invest in new communication technologies, respondents were asked whether they were likely to regularly use four different technology options if they were provided. Figure 7 shows that respondents were fairly evenly split in their views, but were most favourably disposed towards using integrated voice, text and whiteboard technology and least favourably disposed towards using video based discussion technology.

The bivariate analysis showed a moderate association between respondents' nationality or location and their likelihood of regularly using each of the technologies to interact with other students. The association was strongest for text-based instant chat $(V=0.453$ for nationality, sig $=0.000, V=0.330$ for location, sig $=0.008)$ and voice based discussion technology $(V=0.475$ for nationality, sig $=0.000, V=0.321$ for location, sig $=0.014)$. Indian respondents, particularly those living in the Middle East, tended to indicate they were likely to use these technologies, whereas Australian respondents tended to indicate they were either unlikely or unsure. The bivariate analysis also showed a moderate association between respondents' frequency of Internet use and their likelihood of regularly using text based instant chat (gamma = 0.399 , sig $=0.004$ ). More than half of those respondents who use the Internet every day indicated they were likely to use text based instant chat regularly, compared with less than a quarter of those who use the Internet less often. 


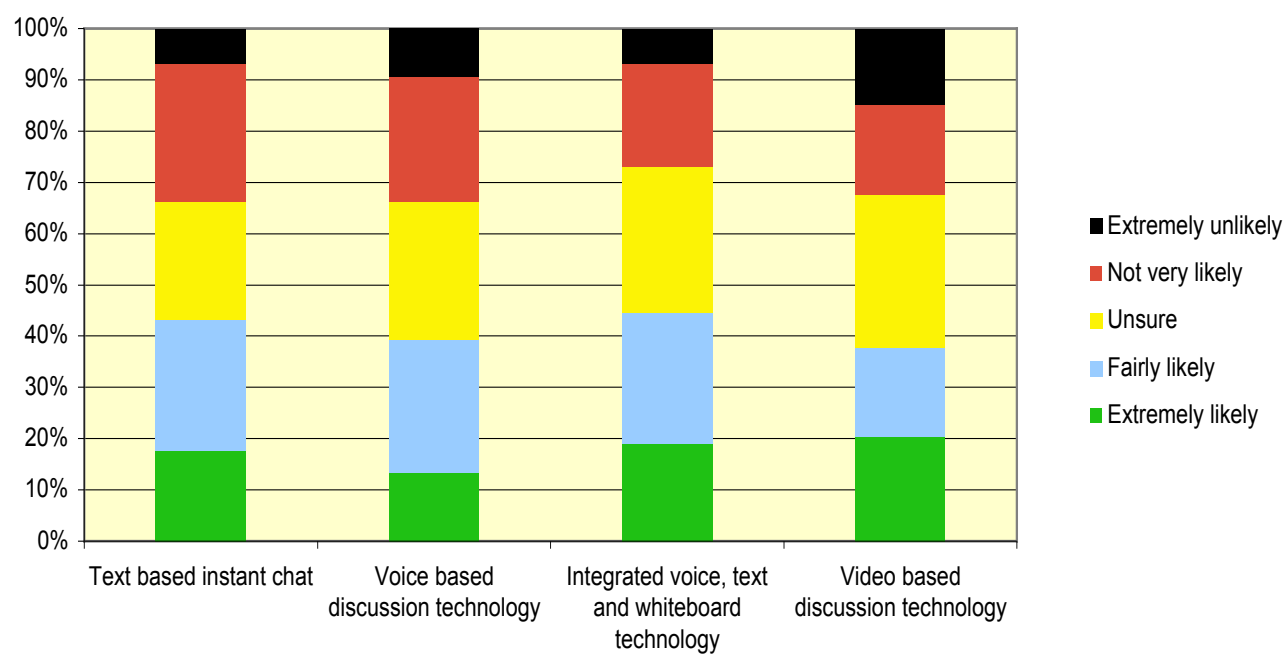

Figure 7: Likelihood of regularly using new communication technologies

\section{Attitudes towards design changes that encourage greater interaction}

Respondents' views were more distinct regarding 12 statements describing how they might feel if the MBA units were redesigned to encourage greater interaction between students. Whilst most of the five positive statements garnered mixed responses, Figure 8 shows that almost $70 \%$ of respondents indicated they would be pleased by such a change, because they think it would improve their learning experience.

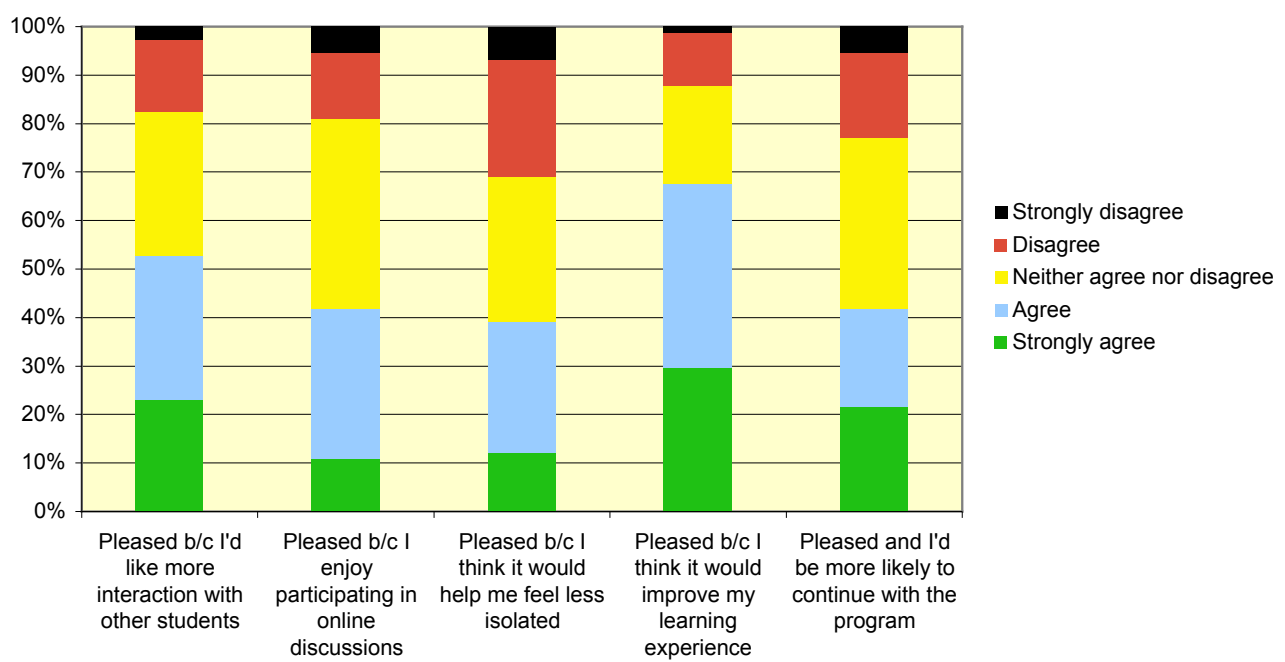

Figure 8: Responses to positive statements regarding redesigning the MBA units

The bivariate analysis showed a moderate association between respondents' nationality and their views on each of these statements. Indian respondents tended to indicate agreement whilst the views of Australians were more evenly spread. The 
association was strongest for the statement that such changes would improve respondents' learning experience $(V=0.388$, sig $=0.004)$. The bivariate analysis also showed a moderate association between respondents' satisfaction with the quantity of discussion posts and the extent to which they agreed they would be pleased with changes because they would like more interaction with other students $(V=0.357$, sig $=$ $0.001)$ and enjoy participating in online discussions $(V=0.318$, sig $=0.017)$. A similar association was found between respondents' satisfaction with the quality of posts and the extent to which they agreed they'd like more interaction with other students $(V=$ 0.334 , sig $=0.006$ ).

Responses to the neutral and negative statements were sometimes more telling. Figure 9 shows that whilst respondents were divided over whether the changes suggested might make them more likely to continue with the program, they overwhelmingly disagreed that such changes would lead them to consider withdrawing from the program. Large proportions also disagreed they would be either unsure about such changes because they lack confidence in their communication skills, or unhappy because they have limited access to the Internet. The bivariate analysis showed a moderate association between gender and the extent to which respondents agreed with this latter statement $(p h i=0.356$, sig $=0.050)$, with women tending more towards agreeing. However, why this was the case was unclear given that the same proportion of men and women who agreed with this statement had no access to the Internet at home.

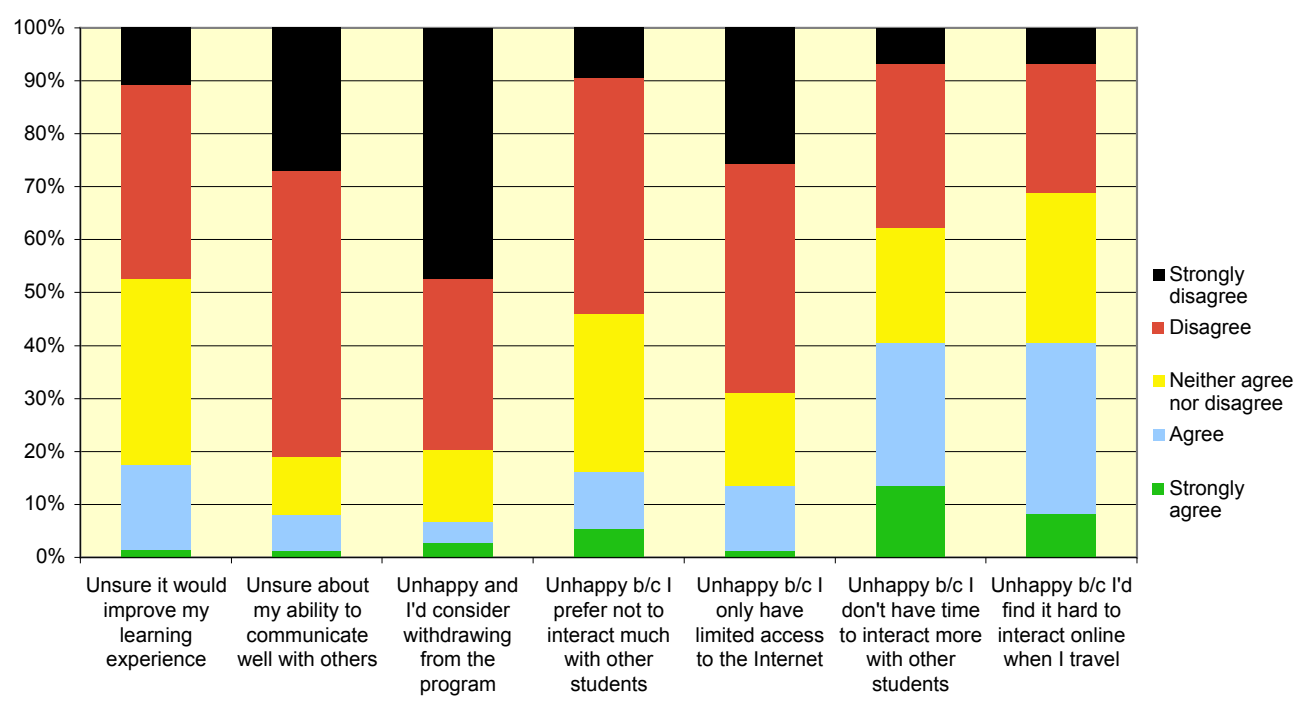

Figure 9: Responses to neutral and negative statements regarding redesigning the MBA units

Respondents were more divided regarding whether their time availability or travel commitments would lead them to be unhappy with such changes; however, $40 \%$ indicated agreement, which is a proportion that cannot be ignored. The bivariate analysis showed a moderate association between respondents' tendency to agree that they would find it difficult to interact online when travelling if they travelled often whilst studying $($ gamma $=0.413$, sig $=0.001)$. 
The bivariate analysis also showed a moderate association between respondents' nationality and the extent to which they agreed they would be unhappy with such changes because they prefer not to interact much with other students $(V=0.355$, sig $=$ $0.016)$ and don't have the time to do so $(V=0.370$, sig $=0.009)$. A similar association was found between respondents' location and the extent to which they agreed they do not have time to interact with other students $(V=0.333$, sig $=0.007)$. Australian respondents tended to express agreement or indifference whereas Indian respondents, particularly those located in the Middle East, tended to express disagreement.

\section{Discussion}

The data collected provides a rich portrait of the attitudes of students enrolled in this MBA program towards interacting with other students. It reveals that whilst the majority of respondents access the Internet regularly and read e-Communities discussion items at least once a week, few participate in such discussions with other students with this level of regularity; indeed, more than a third do not participate in such discussions at all. This finding is congruent with that of Kear (2004), who similarly found a large disparity between the extent to which students accessed online discussion forums and the extent to which they actively participated in forum discussions.

By far the most common reason cited by respondents for this low level of active participation was a lack of time to do so; this is consistent with the findings of many studies in the literature including Fung (2004), Kear (2004), and Motteram and Forrester (2005). However, the array of reasons cited by respondents highlight the role of not only personal circumstances and preferences but also course design and delivery in contributing to the overall level of interaction between students. This is reminiscent of Liu's (2008) finding that five interrelated factors affect interaction between students in distance education courses: students' learning styles and preferences; students' perception of the nature of distance education courses; the way students managed their time and other commitments; the instructor's teaching style and course design; and the course subject matter and level of difficulty.

Respondents are sharply divided in the extent to which they are satisfied with the quantity and quality of e-Communities discussions. Half are broadly satisfied and comment that such discussions give them access to others' experiences and views, help them learn and complete assignments, are generally useful or are simply all that can be expected from busy professionals. However, more than a third are dissatisfied because they would like more discussion and participation, feel the discussions that do occur are mundane and lacking in depth, or simply desire a richer learning experience. Whilst other studies in the literature report similarly diverse views, none show a group of students so evenly split.

In an effort to develop a more holistic understanding of students' interaction behaviours, the study also sought to identify the extent to which students engaged in a 'parallel underworld' (JISC, 2007) of interaction with other students outside the eCommunities forums. However, the data shows that only $30 \%$ of respondents do so, and only two use the synchronous online technologies Skype or instant chat. This suggests that whilst a 'parallel underworld' of interaction certainly exists, it is not as large or technologically oriented as might have been thought. 
Most of the reasons given by respondents for interacting with students outside e-Communities were remarkably similar to the benefits of online interaction cited by students in the study by O'Reilly and Newton (2002): networking and the development of friendships; an enriched learning experience through discussion of issues and sharing of insights; moral support; and the use of peer pressure to keep up with the study schedule. With so few respondents participating actively in e-Communities discussions, it is not possible to make a direct comparison of the reasons given for interacting with other students through e-Communities and outside e-Communities. However, a comparison can be made with the reasons given by respondents for being satisfied with the quantity or quality of e-Communities discussions, and it is noticeable that the only common reason cited is the opportunity to discuss issues and share experiences and insights. This suggests that the respondents who are interacting with students outside e-Communities may be gaining benefits that e-Communities could deliver but is not doing so at present.

Some form of moderate association might have been anticipated between the regularity with which respondents read or actively participated in e-Communities discussions with other students, the extent to which they interacted with students outside e-Communities and/or their level of satisfaction with the quantity and quality of e-Communities discussions. Whilst none was found, an interesting symmetry emerged between the qualitative reasons given by respondents who were dissatisfied with the quantity of discussion posts on e-Communities because they desired a richer learning experience, and those who chose to interact with other students outside eCommunities because discussing content and issues with others enriches their learning experience. This raises the interesting question of whether there are students who are aware of missed learning experiences and are able to find them outside the eCommunities environment, and others who are equally aware but unable to do so; it also raises the question of whether there are others still who simply 'don't know what they don't know' and whose responses to some questions may be coloured by this absence of understanding and knowledge.

The most significant pattern to emerge from the data was a division in attitudes according to nationality and location regarding possible changes to the design of the MBA units that would facilitate and encourage more frequent, meaningful, online interaction between students. Again and again, the data shows a clear tendency for Indian respondents, particularly those located in the Middle East, to be less satisfied with the status quo and considerably more interested in changes that facilitate greater interaction between students. Australian respondents exhibited the reverse tendencies whilst respondents of other nationalities tended to be divided in their views. The anomaly of having so many Indian respondents reporting from the Middle East raises questions regarding the validity of this pattern. However, even when these 12 respondents are excluded from the data analysis, most of the associations discussed in the results section of this paper lessen slightly but remain within the moderate range. The pattern therefore appears to be valid. This suggests that whilst there may be some truth to the speculation in the introduction of this paper that many students choose this MBA program precisely because they are free to study independently without interacting extensively with others, it is mainly true of some of the Australian students and not so of their Indian counterparts.

The other significant pattern to emerge from the data was the substantial proportion of respondents who indicated they would be unhappy if changes were made that 
encouraged greater interaction between students, because they lack the time to interact more or would find it difficult to do so when travelling. Whilst the proportion of respondents who expressed this sentiment was not an outright majority, it was large enough to suggest that for any changes to the program to be successful they must accommodate their needs.

In addition to these clear differences in respondents' attitudes, a number of significant commonalities emerged from the data that cross cultural and other boundaries. Most respondents agree they would be pleased by such changes because they would improve their learning experience, and disagree that they would be either unhappy about such changes because they only have limited access to the Internet, or unsure because they lack confidence in their ability to communicate well with others. When considered in conjunction with other findings from this study, parallels can be seen with the observation of Su et al. (2005) that whilst almost all of the MBA students they surveyed thought interacting with other students enhanced their learning experience, they varied greatly in the extent to which they actually desired such interactions and generally accepted lower interaction levels as a natural result of their busy lives.

Perhaps the most important commonality identified from the data is that most respondents disagreed that changes of the nature suggested would lead them to consider withdrawing from the MBA program. This suggests that the risk inherent in making such changes is lower than might have been thought; that even if such changes were to be poorly received by students, the effect on Chifley's enrolment numbers and revenue is unlikely to be significant.

\section{Conclusions and further research}

The results from this study show a sharp division in respondents' satisfaction levels with the quantity and quality of e-Communities discussion posts. The division seems to predominantly occur along nationality lines, with Indian students significantly more likely to express a desire for greater interaction than Australian students. This suggests there may be a fundamental difference in the attitudes, expectations and preferences of Australian and Indian distance education students, something not identified in the literature search for this study. Why this may be the case is unclear, and it is difficult to know whether these results are specific to this program or indicative of a general difference between Australian and Indian students. Further research by other higher education providers might begin to shed light on this question. Either way, this finding presents a significant challenge for this program in identifying a way forward that will meet the interaction needs of those dissatisfied with the status quo without disenfranchising those who are broadly satisfied. In an attempt to better understand and perhaps resolve this challenge, the next phase of this study explores respondents' views on a concrete scenario of what a modest increase in interaction levels might involve.

Given the level of division amongst respondents regarding the extent to which they might like to interact with each other in the future online, it is difficult to argue there would be value for Chifley in investing in the purchase of commercial communication technologies such as Elluminate or Wimba which are widely used in the Australian university sector. However, the noticeable tendency for Indian students to express interest in being able to interact more with other students using synchronous technologies makes it worthwhile exploring whether it might be possible to achieve 
this through free publicly available technologies such as Skype. The next phase of this project therefore examines respondents' familiarity with Skype and whether they would use it to interact with other students if they were encouraged to do so.

Finally, a new line of thought was opened up by comments from respondents highlighting how the segregated nature of e-Communities prevents course-wide communication and suggesting that face to face social events might be preferable to an increase in online interaction. These comments hark back to the finding of Stodel et al. (2006) that some distance education students miss the informal social interactions offered by face to face communication and find each of the various online communication technologies lacking. This challenges the whole notion of applying a social-constructivist approach to this program by redesigning units to encourage greater online interaction. It raises the possibility that successful distance education programs based on the instructional model may stand to benefit more by creating avenues for face to face interaction than by trying to increase the level and quality of online interaction. The next phase of this project explores the appeal of this idea, however, further research is required beyond this program to test the veracity of this possibility.

\section{References}

Anderson, T. (2002). An updated and theoretical rationale for interaction. ITFORUM, Paper \#63. [viewed 26 Jan 2008] http:/ / it.coe.uga.edu/itforum/paper63/paper63.htm

Anderson, T. (2004). Teaching in an online learning context. In T. Anderson \& F. Elloumi (Eds.), Theory and practice of online learning (pp. 273-294). [viewed 26 Jan 2008, verified 9 Jan 2010] http://cde.athabascau.ca/online_book/

Beyth-Marom, R., Saporta, K. \& Caspi, A. (2005). Synchronous vs. asynchronous tutorials: factors affecting students' preferences and choices. Journal of Research on Technology in Education, 37(3), 245-262.

Creswell, J. W. (2003). Research design: Qualitative, quantitative and mixed methods approaches (2nd ed.). Thousand Oaks, CA: Sage Publications.

Creswell, J. W. \& Plano Clark, V. L. (2007). Designing and conducting mixed methods research. Thousand Oaks, CA: Sage Publications.

Duffy, T. M. \& Jonassen, D. (Eds.) (1992). Constructivism and the technology of instruction: A conversation. Hillsdale NJ: Lawrence Erlbaum Associates.

Fung, Y. Y. H. (2004). Collaborative online learning: Interaction patterns and limiting factors. Open Learning, 19(2), 135-149.

Hatch, S. (2002). The online university: The students' perspective. In Winds of change in the sea of learning. Proceedings ASCILITE Auckland 2002 (pp. 241-249). Auckland: Unitec Institute of Technology. http:// www.ascilite.org.au/ conferences/auckland02/proceedings/ papers/119.pdf

Holmes, B., Tangney, B., FitzGibbon, A., Savage, T. \& Mehan, S. (2001). Communal constructivism: Students constructing learning for as well as with others. In C. Crawford et al. (Eds.), Proceedings of Society for Information Technology and Teacher Education International Conference 2001 (pp. 3114-3119). Chesapeake, VA: AACE. [verified 9 Jan 2010] http: / / www.scss.tcd.ie/ publications/ tech-reports / reports.01/TCD-CS-2001-04.pdf 
JISC (2007). In their own words: Exploring the learner's perspective on e-learning. Higher Education Funding Council for England (HEFCE). [viewed 30 May 2008, verified 9 Jan 2010] http:/ / www.jiscinfonet.ac.uk/publications/in-their-own-words /

Ke, F. \& Carr-Chellman, A. (2006). Solitary learner in online collaborative learning: A disappointing experience? The Quarterly Review of Distance Education, 7(3), 249-265.

Kear, K. (2004). Peer learning using asynchronous discussion systems in distance education. Open Learning, 19(2), 151-164.

Kelsey, K. D. \& D'Souza, A. (2004). Student motivation for learning at a distance: Does interaction matter? Online Journal of Distance Learning Administration, 7(2). [verified 9 Jan 2010] http:/ / www.westga.edu/ distance/ojdla/summer72/ kelsey72.html

Kim, K-J., Liu, S. \& Bonk, C. J. (2005). Online MBA students' perceptions of online learning: Benefits, challenges, and suggestions. The Internet and Higher Education, 8, 335-344.

Lin, L., Cranton, P. \& Bridglall, B. (2005). Psychological type and asynchronous written dialogue in adult learning. Teachers College Record, 107(8), 1788-1813.

Liu, S. (2008). Student interaction experiences in distance learning courses: A phenomenological study. Online Journal of Distance Learning Administration, 11(1). [verified 9 Jan 2010] http:/ / www.westga.edu/ distance/ojdla/spring111/Liu111.html

Moore, M. G. (1993). Three types of interaction. In H. Keith, J. Magnus \& D. Keegan (Eds.), Distance education: New perspectives (pp. 19-24). London: Routledge.

Motteram, G. \& Forrester, G. (2005). Becoming an online distance learner: What can be learned from students' experiences of induction to distance programmes? Distance Education, 26(3), 281-298.

Okada, A. L. P. (2005). The collective building of knowledge in collaborative learning environments. In T. S. Roberts (Ed.), Computer-supported collaborative learning in higher education (pp. 70-99). Hershey, PA: Idea Group Publishing.

O'Reilly, M. \& Newton, D. (2002). Interaction online: above and beyond requirements of assessment. Australian Journal of Educational Technology, 18(1), 57-70. http: / / www.ascilite.org.au/ajet18/oreilly.html

Rosenberg, M. (1968). The logic of survey analysis. New York: Basic Books.

Stodel, E. J., Thompson, T. L. \& MacDonald, C. J. (2006). Learners' perspectives on what is missing from online learning: Interpretations through the community of inquiry framework. The International Review of Research in Open and Distance Learning, 7(3). http:/ / www.irrodl.org/index.php/irrodl/article/view/325/743

Su, B., Bonk, C. J., Magjuka, R. J., Liu, X. \& Lee, S. (2005). The importance of interaction in webbased education: A program-level case study of online MBA courses. Journal of Interactive Online Learning, 4(1). http:/ / www.ncolr.org/jiol/issues/ PDF/4.1.1.pdf

Vygotsky, L. S. (1978). Mind in society: The development of higher psychological processes. Cambridge, MA: Harvard University Press.

Yildiz, S. \& Chang, C. (2003). Case studies of distance students' perceptions of participation and interaction in three asynchronous web-based conferencing classes in the U.S. Turkish Online Journal of Distance Education, 4(2). http:/ / tojde.anadolu.edu.tr/tojde10/articles/ senem.htm 


\section{Appendix: Survey}

\section{A little about yourself}

1. What is your gender?
$\square$ Female
a Male

2. What is your age?
口 20-25
口 26-30
口31-35
구 $36-40$
口41-45 $\quad \square 46-50$
口 Over 50

3. What is your nationality?

australian

Indian

Other (please specify)

4. Where you are currently living?

Australian capital city

Australian regional city (e.g. Geelong, Newcastle, Cairns)

Australian $\mathrm{rural} / \mathrm{remote}$ town

New Zealand

India

$\square$ China

Middle East

$\square$ UK/Europe

U US/Canada

Africa

$\square$ Other (please specify)

5. How many hours per week on average do you work in paid employment?
$\square 36-40$
$\begin{array}{lll}\text { loyment } & \square 1-15 & \square 16-30 \\ \square 41-45 & \square 46-50 & \square 51-55\end{array}$
$\begin{array}{lll}\square \text { loyment } & \square 1-15 & \square 16-30 \\ \square 41-45 & \square 46-50 & \square 51-55\end{array}$

$\square$
I'm not
a $31-35$
560

$\square$ More than 60

6. How many units in the MBA program have you completed or enrolled in to date?
$\square 1$
$\square 2$
ㄱ 3 or 4
a 5 or 6

$\square 7$ or 8

$\square$ or 10

11 or 12

7. How regularly do you currently use the Internet for study or pleasure?
$\square$ Every day

Several times a week

About once a week

About once or twice a month

Less than once a month

8. How do you currently access the Internet for your studies? (Tick all applicable boxes)

At home using dial-up

At home using broadband or another high speed connection

$\square$ At work using dial-up

At work using a high speed connection

Through an Internet café

$\square$ In hotels using dial-up

In hotels using broadband or another high speed connection

$\square$ Other (please specify) 
9. Do you travel and spend time away from home during your studies?

Yes, occasionally

$\square$ Yes, often

$\square$ No

10. If you answered 'yes' to the previous question, do you usually have reliable Internet access while you're away?

$\square$ Yes

$\square$ No

Not applicable

\section{e-Communities and interacting with others}

11. How often do you read e-Communities discussion postings when you are studying?

$\square$ Every day

$\square$ Several times a week

About once a week

About once or twice a month

Less than once a month

Never

12. How often do you post e-Communities discussion postings to other students (not the Unit Chair) when you are studying?

$\square$ Every day

Several times a week

About once a week

About once or twice a month

Less than once a month

Never

Please briefly explain why you post this often or this little.

13. How satisfied are you with the amount of discussion that currently occurs between students on e-Communities?

$\square$ Extremely satisfied

$\square$ Fairly satisfied

$\square$ Not very satisfied

Not at all satisfied

Don't care/don't have an opinion

Please briefly explain why.

14. How satisfied are you with the quality of discussion that currently occurs between students on e-Communities?

Extremely satisfied

$\square$ Fairly satisfied

Not very satisfied

Not at all satisfied

Don't care/don't have an opinion

Please briefly explain why.

15. Do you interact with other students outside e-Communities?

$\square$ Yes

No (you can skip the next 3 questions and will be taken straight to question 19) 


\section{Interacting with others outside e-Communities}

16. How regularly do you interact with other students outside e-Communities?

$\square$ Every day

Several times a week

About once a week

About once or twice a month

$\square$ Less than once a month

Never

17. What modes of communication do you use? (Tick all applicable boxes)

$\square$ Email

Meet face to face

$\square$ Talk on telephone

Talk using Skype

Use online instant chat (e.g. MSN Messenger, Yahoo Groups)

$\square$ Other (please specify)

18. Briefly explain why you have chosen to interact with other students outside eCommunities.

\section{Considering the future}

19. Please indicate how strongly you agree or disagree with each of the following statements. $\mathrm{SA}=$ Strongly Agree $\mathrm{D}=$ Disagree
$\mathrm{A}=$ Agree
$\mathrm{SD}=$ Strongly Disagree
$\mathrm{N}=$ Neither Agree Nor Disagree

I would like to be able to...

a. Interact more with other students in real time.

b. See and hear other students in different Australian and international locations.

c. Interact more with other students face to face.

d. Share documents, images and pictures with other students more easily.

20. If Chifley added the following communication technologies to e-Communities, how likely is it that you would use them regularly to interact with other students?

\begin{tabular}{|l|l|l|l|l|l|}
\hline & $\begin{array}{c}\text { Extremely } \\
\text { likely }\end{array}$ & $\begin{array}{c}\text { Fairly } \\
\text { likely }\end{array}$ & Unsure & $\begin{array}{c}\text { Not very } \\
\text { likely }\end{array}$ & $\begin{array}{c}\text { Extremely } \\
\text { unlikely }\end{array}$ \\
\hline a. $\begin{array}{l}\text { Text based instant chat (similar to } \\
\text { MSN Messenger). }\end{array}$ & & & & & \\
\hline b. $\begin{array}{l}\text { Voice-based 'real time' } \\
\text { discussion technology. }\end{array}$ & & & & & \\
\hline c. $\begin{array}{l}\text { Integrated voice, text and } \\
\text { whiteboard technology. }\end{array}$ & & & & & \\
\hline d. Video based 'real time' \\
discussion technology.
\end{tabular}


21. Please indicate how strongly you agree or disagree with the following statements. $\mathrm{SA}=$ Strongly Agree $\quad \mathrm{A}=$ Agree $\quad \mathrm{N}=$ Neither Agree Nor Disagree $\mathrm{D}=$ Disagree

$\mathrm{SD}=$ Strongly Disagree

If Chifley changed the design of the units in the MBA program to actively facilitate and encourage greater interaction between students online, I would be...

\begin{tabular}{|c|c|c|c|c|c|}
\hline & SA & A & $\mathrm{N}$ & $\mathrm{D}$ & SD \\
\hline Pleased, because I'd like more interaction with other students. & & & & & \\
\hline b. Pleased, because I enjoy participating in online discussions. & & & & & \\
\hline c. Unhappy, because I prefer not to interact much with other students. & & & & & \\
\hline d. Unhappy, because I only have limited access to the Internet. & & & & & \\
\hline e. Pleased, because I think it would help me feel less isolated. & & & & & \\
\hline $\begin{array}{l}\text { f. Unsure, because I'm not confident about my ability to communicate } \\
\text { well with others. }\end{array}$ & & & & & \\
\hline $\begin{array}{l}\text { g. Unhappy, because I don't have the time to interact more with other } \\
\text { students. }\end{array}$ & & & & & \\
\hline $\begin{array}{l}\text { h. Unhappy, because I'd find it difficult to participate in online } \\
\text { discussions when I travel. }\end{array}$ & & & & & \\
\hline i. $\quad$ Pleased, because I think it would improve my learning experience. & & & & & \\
\hline Pleased, and I would be more likely to continue with the program. & & & & & \\
\hline $\begin{array}{l}\text { k. Unsure, because I don't know whether it would improve my } \\
\text { learning experience. }\end{array}$ & & & & & \\
\hline Unhappy, and I would consider withdrawing from the program. & & & & & \\
\hline
\end{tabular}

Sharon Watson worked previously as an instructional designer at Chifley Business School in Melbourne and at Charles Darwin University, and now resides in Canberra. Email: eduresearchmail-mba@yahoo.com.au 